\title{
Rancang Bangun Sistem Informasi Pengelolaan Data Occupational Health and Safety Handling PT.CPL
}

\author{
Henderi $^{1}$, Mulyati*2, Yunia Riska Anggrahini ${ }^{3}$ \\ ${ }^{1,3}$ Program Studi Sistem Informasi Universitas Raharja \\ ${ }^{2}$ Program Studi Manajemen Retail Universitas Raharja \\ E-mail: 1'henderi@ raharja.info, *2mulyati@ raharja.info, ${ }^{3}$ yuniariska@ raharja.info
}

\begin{abstract}
Abstrak
Pelaksanaan program Occupational Health and Safety Handling (Program K3/ Kesehatan dan Keselamatan Kerja) pada suatu perusahaan dapat membuat produktivitas dan kinerja karyawan semakin meningkat. Pekerjaan akan diselesaikan dengan baik jika karyawan memiliki rasa aman dan nyaman ditempatnya bekerja. PT.CPL (Cipta Perdana Lancar) penanganan Occupational Health and Safety Handling-nya belum maksimal, permasalahan terjadi dikarenakan masih terdapat beberapa kekurangan, salah satunya pada sisi sistem informasinya sehingga pada pelaksanaannya menjadi belum rapi dan belum terstruktur selain itu masih banyak kekurangankekurangan lainnya. Untuk itulah diperlukan pembaharuan sistem informasi yang lebih akurat dan sistem yang cepat menangani permasalahan Occupational Health and Safety Handling di perusahaan tersebut. Untuk melengkapi penelitian ini maka diperlukan beberapa metode, diantaranya untuk metode pengumpulan data membutuhkan Pengamatan langsung, kemudian berlanjut dengan interview kepada Stakeholders dan mencari sumber teori penelitian dengan studi pustaka. Metode analisa penelitian ini memakai Analisa SWOT serta penggambaran desain sistemnya dengan UML yang berorientasi objek. Metode-metode yang digunakan tersebut sebagai dasar dari rancang bangun penelitian ini yang kemudian menghasilkan sebuah Sistem Informasi Pengelolaan Data Occupational Health and Safety Handling yang dibuat dengan berbasis Web sebagai solusi dari masalah-masalah yang terjadi di PT.CPL tersebut.
\end{abstract}

Kata Kunci : Sistem Informasi, Occupational Health and Safety Handling, Web.

\begin{abstract}
The implementation of the Occupational Health and Safety Handling program in a company can increase employee productivity and performance. The job will be done well if employees have a sense of security and comfort in their place of work. PT.CPL (Cipta Perdana Lancar) the handling of Occupational Health and Safety Handling is not optimal, problems occur because there are still several shortcomings, one of which is on the information system side so that the implementation is not neat and unstructured besides that there are still many other deficiencies. For this reason, it is necessary to update the information system that is more accurate and a system that quickly handles Occupational Health and Safety Handling problems in the company. To complete this research, several methods are needed, including data collection methods requiring direct observation, then continuing with interviews with stakeholders and looking for sources of research theory with literature study. The method of analysis of this research uses SWOT analysis and the depiction of the system design with objectoriented UML. The methods used are the basis for the design of this research which then results in a Web-based Occupational Health and Safety Handling Data Management Information System as a solution to the problems that occur in PT.CPL.
\end{abstract}

Keywords: Information Systems, Occupational Health and Safety Handling, Web. 


\section{PENDAHULUAN}

PT. CPL (Cipta Perdana Lancar) merupakan perusahaan yang memproduksi Sparepart Kendaraan Bermotor. Pada saat PT.CPL memproduksi Part bracket ataupun Trap Comp didalam proses BPB (Blank-Pierching-Bending)nya menggunakan mesin seberat 80 hingga 100 ton. Untuk kenyamanan dan keselamatan para karyawannya perihal ini, PT.CPL memberikan asuransi BPJS kepada seluruh karyawannya. Dilihat dari data PT.CPL di tahun 2017 jumlah karyawan yang mengalami kecelakaan kerja (work accident) mencapai $1,1 \%$, setelah diteliti lebih lanjut, hal ini terjadi dikarenakan kedua unsur ini yaitu kelalaian manusia/factor manusia/Unsafe Action dan factor lingkungan/Unsafe Condition. Kedua hal tersebut menjelaskan bahwa perilaku manusia (dalam hal ini Karyawan) menjadi faktor penyebab terjadinya kecelakaan di tempat kerja. Dari kondisi tersebut, PT.CPL membutuhkan sebuah sistem baru dengan sistem informasi yang khusus menangani kecelakaan kerja, hal ini dimaksudkan agar jika terjadi kecelakaan kerja, data kejadian dapat langsung ditangani dan diproses oleh pihak BPJS. Sistem PT.CPL saat itu memiliki beberapa kekurangan, contohnya jika terjadi kecelakaan kerja maka untuk pencarian data karyawan tersebut memakan waktu yang cukup lama, pihak HRD harus mencari data karyawan dengan meminta ID BPJS ataupun ID KTP-nya dan Karen ahl inilah maka sering terjadi keterlambatan laporan terhadap pihak BPJS. Dengan kurang maksimalnya penanganan Occupational Health and Safety Handling tersebut karyawan menjadi tidak nyaman dalam bekerja. Untuk itulah diperlukannya Sistem Informasi yang baru agar pada pelaksanaan pelaporannya menjadi rapi dan terstruktur. Untuk itulah maka penelitian ini dibuat untuk dapat diimplementasikan oleh PT.CPL.

\section{TINJAUAN PUSTAKA}

Tinjauan pustaka untuk melengkapi penelitian ini berupa definisi dari teori-teori yang menguatkan penelitian, antara lain :

\section{Sistem Informasi}

Sistem Informasi adalah Sistem yang berada pada sebuah instansi/organisasi/perusahaan yang menggabungkan kebutuhan pengelolaan data transaksi harian untuk mendukung kegiatan operasional, manajerial, strategi organisasi/perusahaan untuk diberikan kepada pihak luar dalam bentuk Laporan.[1]

\section{Data}

Data adalah Catatan ataupun rangkuman aktivitas real yang berisi tentang kesatuan aktivitas nyata atau fakta-fakta yang menggambarkan objek, orang, yang dinyatakan oleh suatu Nilai (nilai dapat berupa angka, karakter maupun simbol-simbol lainnya).[2]

\section{Occupational Health}

Occupational Health atau Kesehatan Kerja adalah Kondisi yang berfokus kepada kondisi mental, kondisi fisik dan kondisi emosi dari orang yang melakukan pekerjaan agar selalu dalam kondisi kesehatan yang prima, baik secara fisik maupun baik secara mental.[3]

\section{Safety Handling}

Safety Handling atau Penanganan keamanan dalam keselamatan kerja adalah perlindungan kepada orang yang melakukan pekerjaan kemudian mengalami kecelakaan terkait dengan pekerjaan tersebut dan merupakan protection terhadap kesejahteraan fisik seseorang terhadap injury/cedera yang juga berhubungan dengan pekerjaan yang sedang ditanganinya.[4]

\section{LITERATURE REVIEW}

Literature Review merupakan penelaahan penelitian yang sudah dilakukan oleh orang-orang sebelumnya yang penelitiannya memiliki keterkaitan dengan penelitian ini, diantaranya adalah : 
1. Literature Review dari penelitian yang sudah dilakukan oleh Ade Dwiputra dengan judul penelitian: "Analysis of the Implementation of Occupational Health and Safety (K3) in the Payakumbuh City Construction Service Company. Dengan tujuan penelitian untuk mengetahui implementasi K3 pada proyek-proyek konstruksi,khususnya untuk di kota Payakumbuh, serta untuk mengetahui apakah kontraktor telah menerapkan K3 diperusahaannya. Penelitian ini menegaskan bahwa perlu adanya pengawasan yang lebih pada setiap perusahaan jasa kontruksi, terutama kepada para pekerja kontruksi dalam penerapan $\mathrm{K} 3$ disetiap aktivitas kerjanya.[5]

2. Literature Review dari penelitian yang sudah dilakukan oleh R.Hasibuan, dengan judul penelitian: "The Influence of Occupational Health and Safety, Training and Teamwork on the Performance of Medical Personnel at Budi Kemuliaan Hospital". Dengan tujuan penelitian untuk melakukan pendekatan/approach yang digunakan yakni menggunakan Quantitative approach dengan metode penelitian Survey; Pengambilan sampel dari satu populasi, selain itu juga menggunakan Questionnaire sebagai alat pengumpulan data utamanya, maka dapat diambil kesimpulan bahwa Occupational Health and Safety Handling dengan dukungan kerja Team memiliki pengaruh yang kuat dan benilai positif terhadap kinerjakerja para tenaga medis di RS.Budi Kemuliaan.[6]

3. Literature Review dari penelitian yang sudah dilakukan oleh Fenny Moniaga dan Vandasyela Rompis dengan judul penelitian: "Analysis of the Construction Project Health and Safety Management System (SMK3) Using the Hazard Identification And Risk Assessment (HIRA) Method". Dengan tujuan penelitian untuk menjamin pelaksanaan SMK3. Penelitian ini menyarankan agar perusahaan proyek konstruksi perlu mengembangkan Manajemen Resiko berdasar pada identifikasi Risk/Dangerous/bahaya dan penilaian resiko melalui metode HIRA tersebut.[7]

4. Literature Review dari penelitian yang sudah dilakukan oleh Eko Nurmianto dengan judul penelitian: "Hazard Identification and Design of Occupational Health and Safety Information Systems in Ammonia Units (Case Study: PT. Petro Kimia Gersik)". Dengan tujuan langsung pada unit Amoniak untuk melihat identifikasi Hazard-nya serta penanggulangannya. Selain itu bertujuan untuk mendesain sebuah sistem informasi K3 khusus untuk unit Amoniak yang ada di PT.Petro Kimia Gresik.[8]

5. Literature Review dari penelitian yang sudah dilakukan oleh Syafrudin dengan judul "Implementation of Occupational Health and Safety (K3) Construction Cost Evaluation in the Technical Planning Document of the State Budget in the PUPR Office of Riau Province". Tujuan penelitiannya untuk mengetahui jumlah biaya-biaya beserta persentasenya dalam implementasi K3 pada proyek konstruksi. Penelitian ini memakai metode kuantitatif deskriptif dengan menyebarkan Questionnaire sebagai data primer dan RAD/Rencana Anggaran Biaya sebagai data sekundernya.[9]

\section{METODE PENELITIAN}

\section{Metode Pengumpulan Data}

Metode pengumpulan data untuk memperkuat penelitian ini diantaranya :

- Pengamatan Langsung/Observation

Pengamatan langsung dilakukan dengan melihat lebih dekat aktivitas pekerja di PT. CPL untuk diperoleh data-data yang diperlukan pada penelitian ini.

- Wawancara/Interview

Wawancara/Interview perlu dilakukan sebagai usaha untuk mendapatkan informasi yang diperlukan dan berguna untuk penelitian ini. Maka wawancara mengarah kepada pihak-pihak yang berkaitan dengan Occupational Health and Safety Handling yakni 
kepada Manajer HRD PT.CPL : Bpk.Bambang Setyono beserta Kabag HRD-nya yakni Bpk.Bayu Sarjono

- Studi Pustaka/Library Research

Studi pustaka diperlukan sebagai pendukung penelitian yang sifatnya ilmiah, teori dalam penelitian bersumber dari buku-buku, jurnal nasional dan publikasi lainnya sebagai referensi dan memperkaya khazanah penelitian.

\section{Metode Analisa Sistem}

Metode Analisa Sistem didalam penelitian ini yakni analisa SWOT yang memiliki unsur-unsur internal, seperti memiliki unsur Kekuatan (Strengths) dan Kelemahan (Weaknesses) dan memiliki unsur eksternal, seperti memiliki unsur Peluang (Opportunities) dan memiliki unsur ancaman (Threats). Berikut Tabel identifikasi SWOTnya:

Tabel 1. Identifikasi SWOT PT.CPL

\begin{tabular}{|c|c|}
\hline Kekuatan (Strength) & Kelemahan (Weakness) \\
\hline $\begin{array}{l}\text { 1. K3 pada PT.CPL (Cipta Perdana Lancar) telah } \\
\text { berjalan selama } 9 \text { (Sembilan) tahun dan sistem } \\
\text { penanganan K3-nya selalu mengutamakan } \\
\text { karyawan. } \\
\text { 2. PT.CPL terletak di kawasan industri dan pada } \\
\text { jam kerjanya memiliki target produk yang harus } \\
\text { dicapai sehingga perusahaan ini mengutamakan } \\
\text { dan memperhatikan Occupational Health and } \\
\text { Safety Handling para karyawannya. }\end{array}$ & $\begin{array}{l}\text { 1. Belum optimalnya sistem } \\
\text { penanganan Occupational Health } \\
\text { and Safety Handling pada } \\
\text { PT.CPL sehingga perlu untuk } \\
\text { terus ditingkatkan. } \\
\text { 2. Sistem pengelolaan data Occu- } \\
\text { pational Health and Safety } \\
\text { Handling sebelumnya masih } \\
\text { dilakukan secara manual } \\
\text { sehingga kurang tepat sasaran. }\end{array}$ \\
\hline Pelua & (Treats) \\
\hline $\begin{array}{l}\text { 1. Perkembangan ilmu pengetahuan mengenai } \\
\text { Occupational Health and Safety Handling } \\
\text { semakin tinggi yang dapat digunakan untuk } \\
\text { mengembangakan sistem yang ada. } \\
\text { 2. Sebagai perusahaan Sparepart yang baru, } \\
\text { PT.CPL ingin menjalin kerjasama yang baik dan } \\
\text { terpercaya dengan rumah sakit yang } \\
\text { menggunakan BPJS untuk karyawannya. }\end{array}$ & $\begin{array}{l}\text { 1. Dengan keberadaan alat-alat dan } \\
\text { mesin yang berat, jika } \\
\text { karyawannya tidak fokus dan } \\
\text { tidak menggunakan kelengkapan } \\
\text { alat Safety dengan tepat maka } \\
\text { dapat mengakibatkan kecelakaan } \\
\text { kerja. } \\
\text { 2. Kurang maksimalnya sistem } \\
\text { informasiOccupational Health } \\
\text { and Safety Handling dapat } \\
\text { menghambat penanganan } \\
\text { karyawan yang kecelakaan kerja. }\end{array}$ \\
\hline
\end{tabular}

Berdasarkan tabel identifikasi SWOT PT.CPL diatas, maka dilakukan analisa Strategi SWOT seperti tabel di bawah ini : 
Tabel 2. Analisa Strategi SWOT

\begin{tabular}{|c|c|c|}
\hline $\begin{array}{l}\text { Internal } \\
\text { Eksternal }\end{array}$ & $\begin{array}{c}\text { Strengths (S) } \\
\text { Kekuatan }\end{array}$ & $\begin{array}{c}\text { Weaknesses (W) } \\
\text { Kelemahan }\end{array}$ \\
\hline \multirow[b]{2}{*}{$\begin{array}{c}\text { Opportunities } \\
\text { (O) } \\
\text { Peluang }\end{array}$} & $\mathrm{SO}$ & WO \\
\hline & $\begin{array}{l}\text { 1. Membuat sistem informasi } \\
\text { pengelolaan data yang tepat dalam } \\
\text { penanganan Occupa-tional Health } \\
\text { and Safety Handling agar } \\
\text { mempermudah mengidentifikasi } \\
\text { setiap karya-wan yang sudah } \\
\text { menggunakan kelengkapan alat } \\
\text { safety kerja dan yang belum } \\
\text { lemgkap. } \\
\text { 2. Melakukan Sosialisasi kepada } \\
\text { seluruh karyawan PT.CPL tentang } \\
\text { sistem informasi pengelolaan data } \\
\text { Occupational Health and Safety } \\
\text { Handling ini. }\end{array}$ & $\begin{array}{l}\text { 1. PIC yang bertugas } \\
\text { mensosialisasikan sistem } \\
\text { informasi pengelolaan data } \\
\text { Occupational Health and } \\
\text { Safety Handling ini hanya } 2 \\
\text { (dua) orang yakni manajer } \\
\text { HRD dan admin saja. }\end{array}$ \\
\hline \multirow[b]{2}{*}{$\begin{array}{c}\text { Threats (T) } \\
\text { Ancaman }\end{array}$} & ST & WT \\
\hline & $\begin{array}{l}\text { 1. Dikarenakan angka kecelakaan } \\
\text { kerja semakin meningkat, maka } \\
\text { perlu untuk diadakan Training atau } \\
\text { Pelatihan-pelatihan kepada seluruh } \\
\text { karyawan PT.CPL untuk selalu } \\
\text { melengkapi alat Safety kerjanya } \\
\text { didalam melakukan aktivitas } \\
\text { pekerjaan harian sehingga dapat } \\
\text { terhindar dari kecelakaan ditempat } \\
\text { kerja. }\end{array}$ & $\begin{array}{l}\text { 1. Training/pelatihan-pelatihan } \\
\text { yang diadakan oleh PT.CPL } \\
\text { tentang K3 ini } \\
\text { membutuhkan biaya yang } \\
\text { cukup besar dan perlu untuk } \\
\text { dianggarkan rutin oleh } \\
\text { perusahaan setiap tahunnya. }\end{array}$ \\
\hline
\end{tabular}

\section{HASIL DAN PEMBAHASAN}

\section{Diagram Rancangan Sistem}

\section{Usecase Diagram}

Rancangan sistem berupa Usecase Diagram memiliki fungsi untuk menjabarkan hubungan sistem dengan User/pemakai yang disebut Actor. Selain itu, Usecase diagram juga digunakan untuk menjabarkan hubungan interaksi antara sistem dengan User tersebut. 


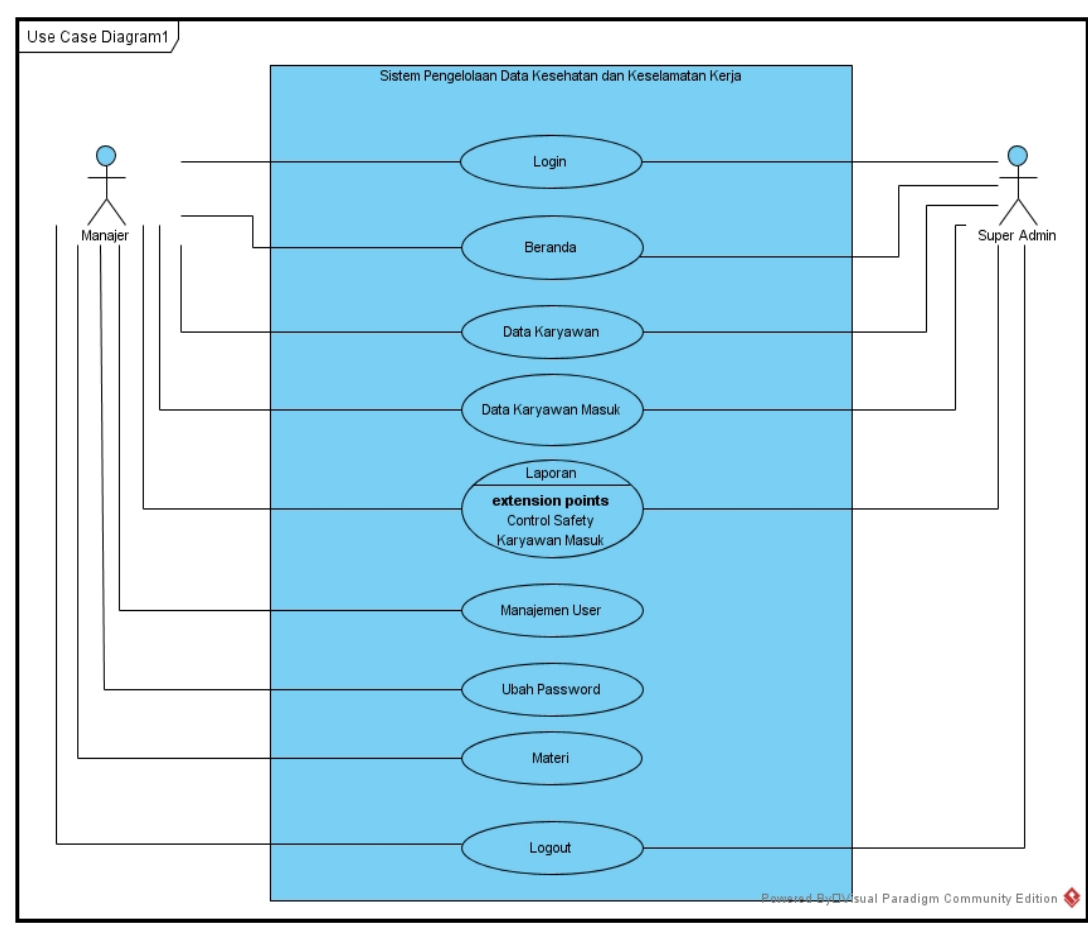

Gambar 1. Usecase Diagram Sistem PT.CPL

Keterangan: Gambar 1 menjelaskan tentang Usecase diagram di PT.CPL yang terdiri atas 2 (dua) Actor yakni Manager dan Super Admin didalam menjalankan sistem pengelolaan data Occupational Health and Safety Handling diperusahaan tersebut.

\section{Activity Diagram}

Rancangan sistem berupa Activity Diagram ini menggambarkan aktivitas dan perilaku pengguna sistem informasi pengelolaan data Occupational Health and Safety Handling yang sedang dirancang. Penggambarannya sebagai berikut :

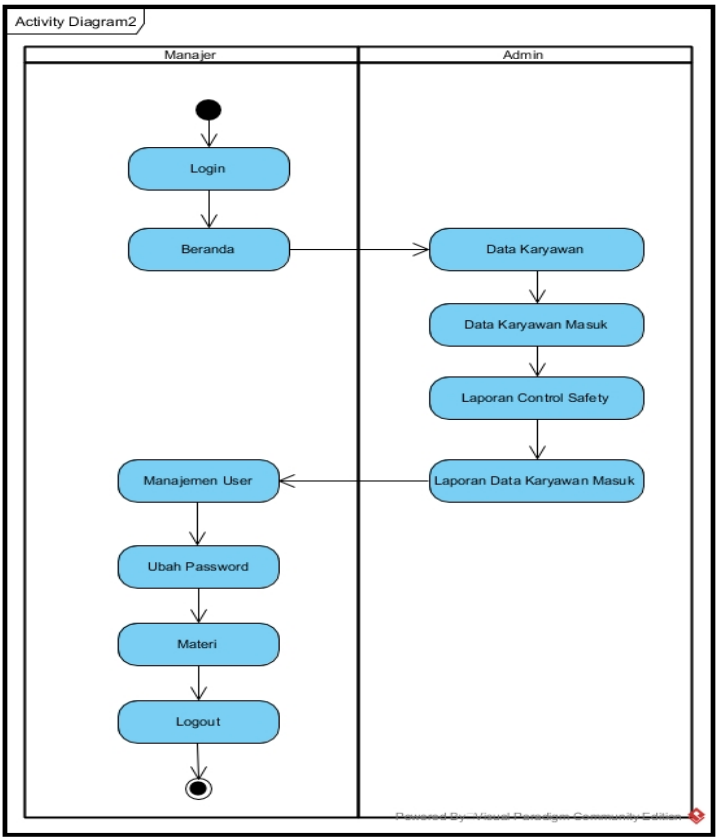

Gambar 2. Activity Diagram PT.CPL 
Keterangan: Gambar 2 menjelaskan tentang Activity Diagram PT.CPL yang menggambarkan alur-alur dari aktivitas/pekerjaan Manajer dan alur aktivitas Admin yang saling berkaitan satu sama lain.

\section{Sequence Diagram}

Rancangan sistem berupa Sequence Diagram ini menggambarkan relation activity menggunakan rancangan sistem informasi pengelolaan data Occupational Health and Safety Handling yang diusulkan ini.

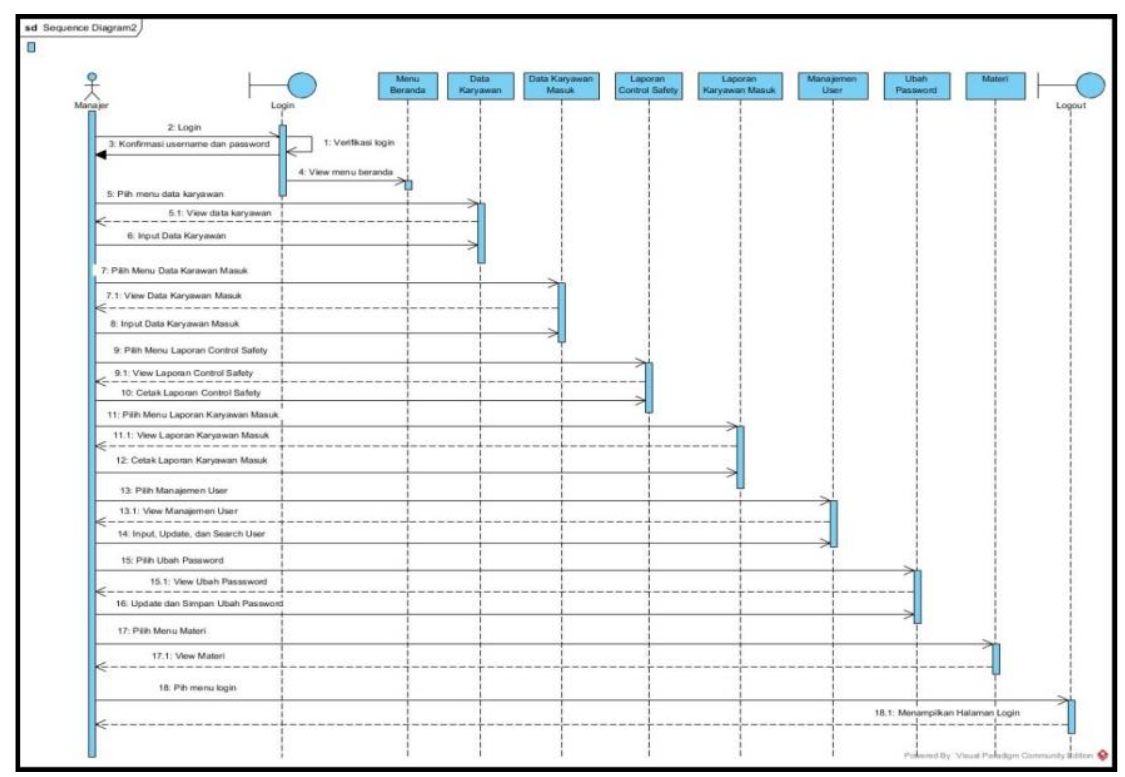

Gambar 3. Sequence Diagram Manajer PT.CPL

Keterangan: Gambar 3 menjelaskan tentang Sequence Diagram Manajer PT.CPL yang menggambarkan alur aktivitas secara detail/rinci pada sistem informasi pengelolaan data Occupational Health and Safety Handling yang diusulkan.

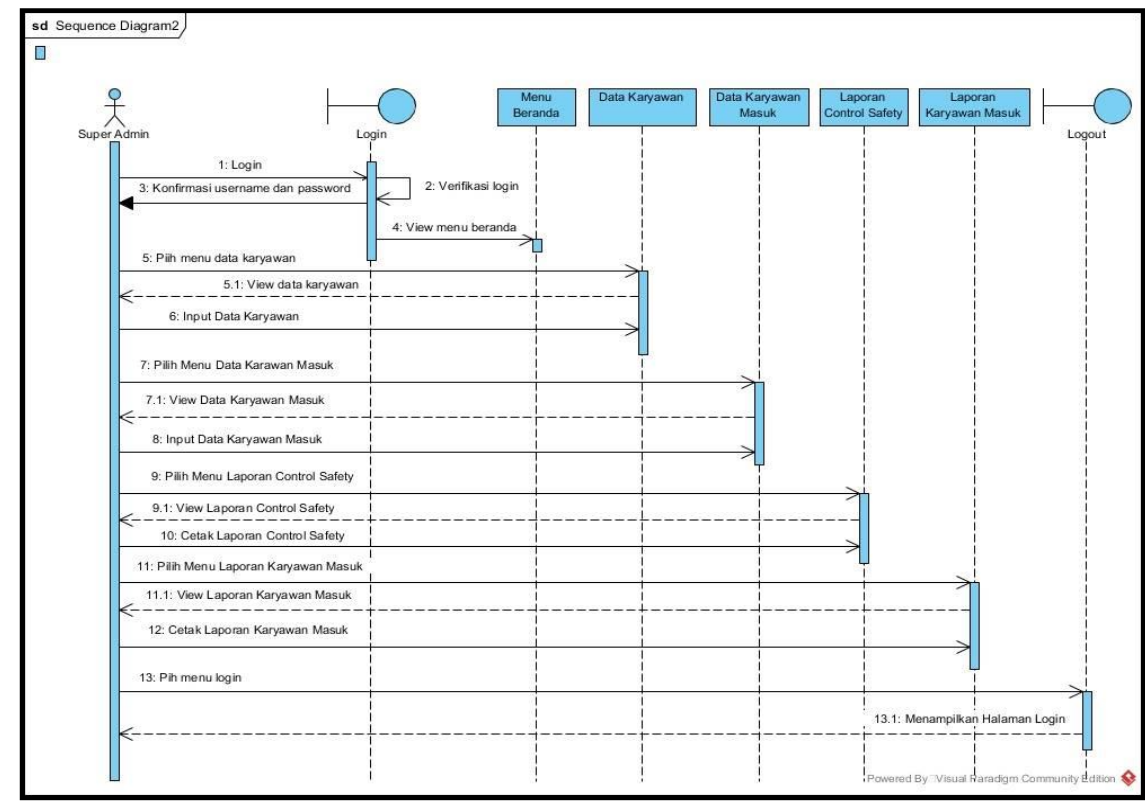

Gambar 4. Sequence Diagram Super Admin 
Keterangan: Gambar 4 menjelaskan tentang Sequence Diagram Super Admin PT.CPL yang menggambarkan alur aktivitas secara detail/rinci pada sistem informasi pengelolaan data Occupational Health and Safety Handling yang diusulkan untuk digunakan oleh PT.CPL tersebut.

\section{Class Diagram}

Class diagram PT.CPL digambarkan sebagai berikut :

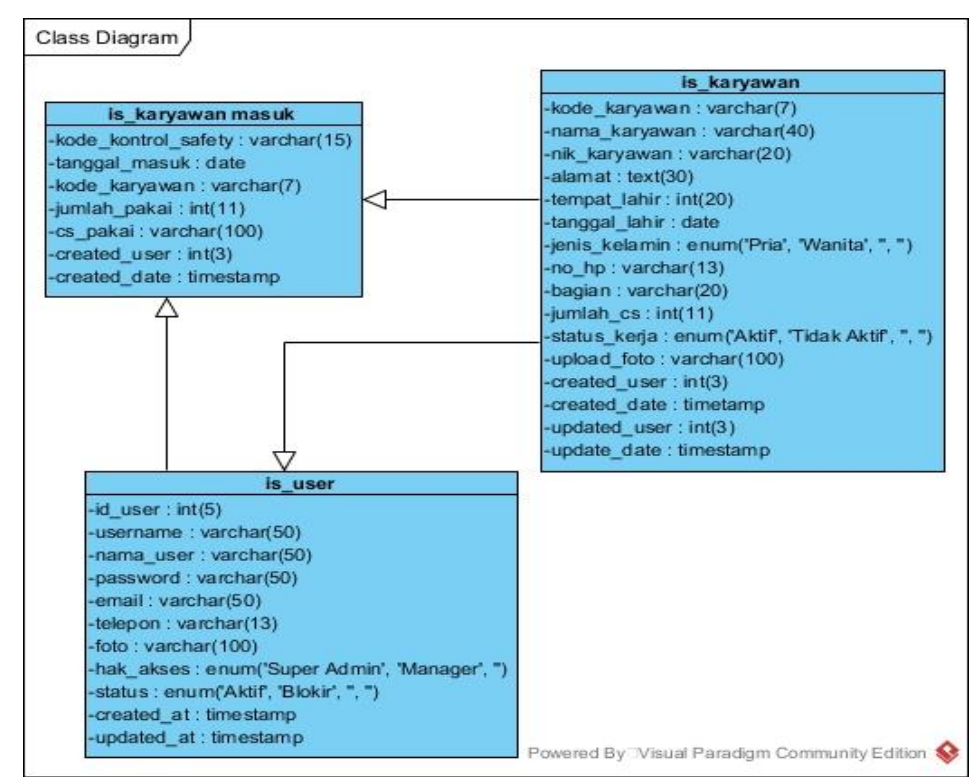

Gambar 5. Class Diagram

Keterangan: Gambar 5 menjelaskan tentang Class Diagram Super Admin PT.CPL yang digunakan untuk menjelaskan spesifikasi tabel Basis Data/Database yang ada di dalam sistem informasi pengelolaan data Occupational Health and Safety Handling di PT.CPL

\section{Desain Rancangan Program}

1. Tampilan Login

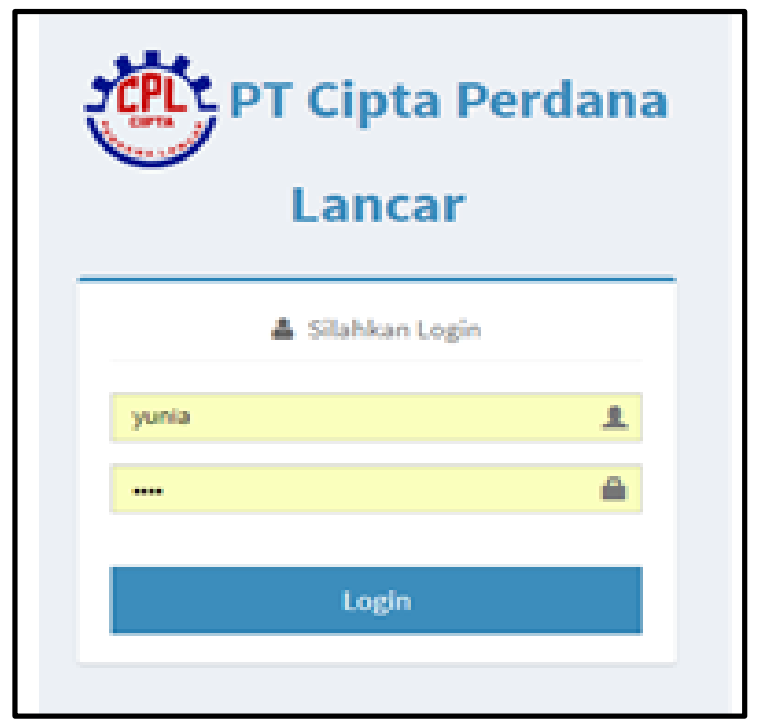

Gambar 6. Tampilan Login 
Keterangan: Gambar 6 menjelaskan tentang Tampilan awal atau Login pada Web Sistem informasi pengelolaan data Occupational Health and Safety Handling yang dibuat untuk PT.CPL.

2. Tampilan Menu Beranda

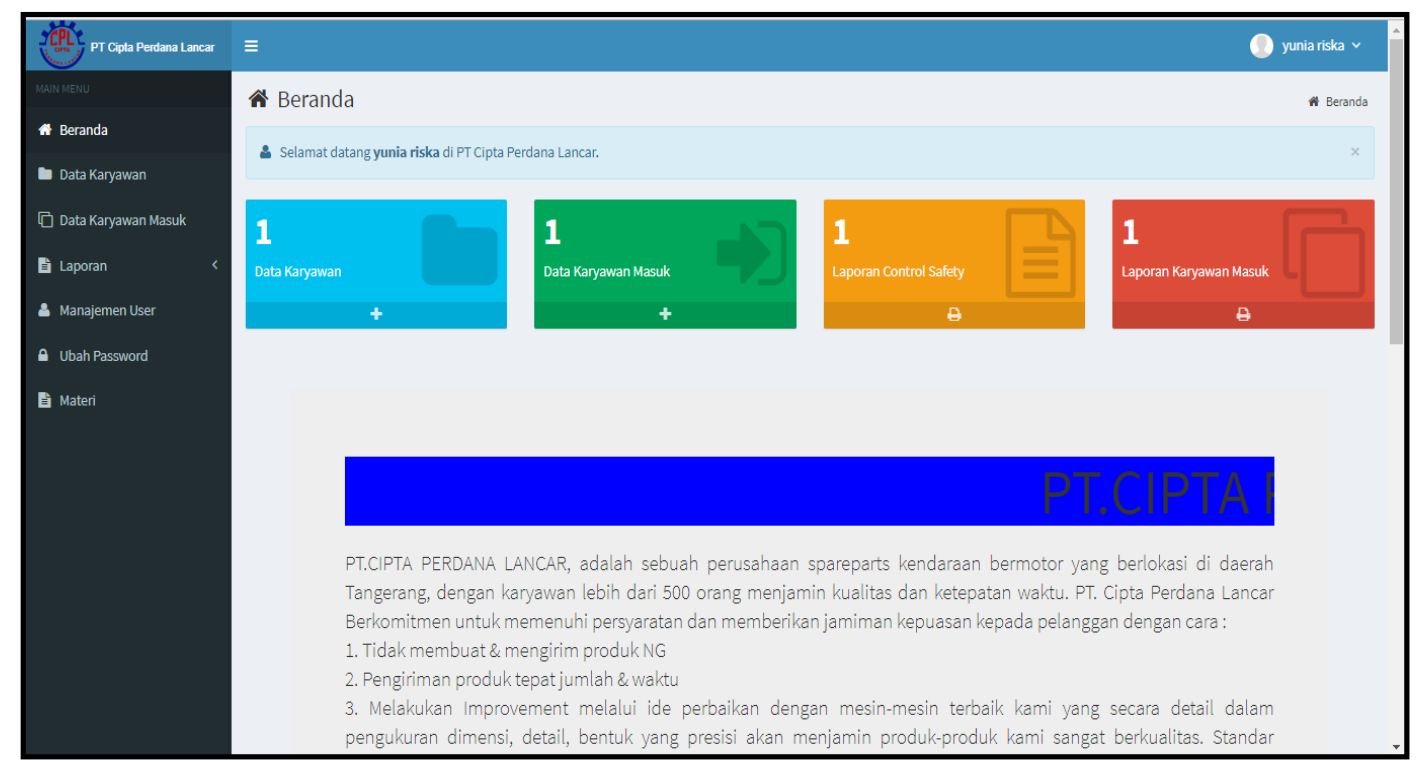

Gambar 7. Tampilan Menu Beranda

Keterangan: Gambar 7 menjelaskan tentang Tampilan Menu Beranda pada Web Sistem informasi pengelolaan data Occupational Health and Safety Handling yang dibuat untuk PT.CPL.

3. Tampilan Menu Data Karyawan

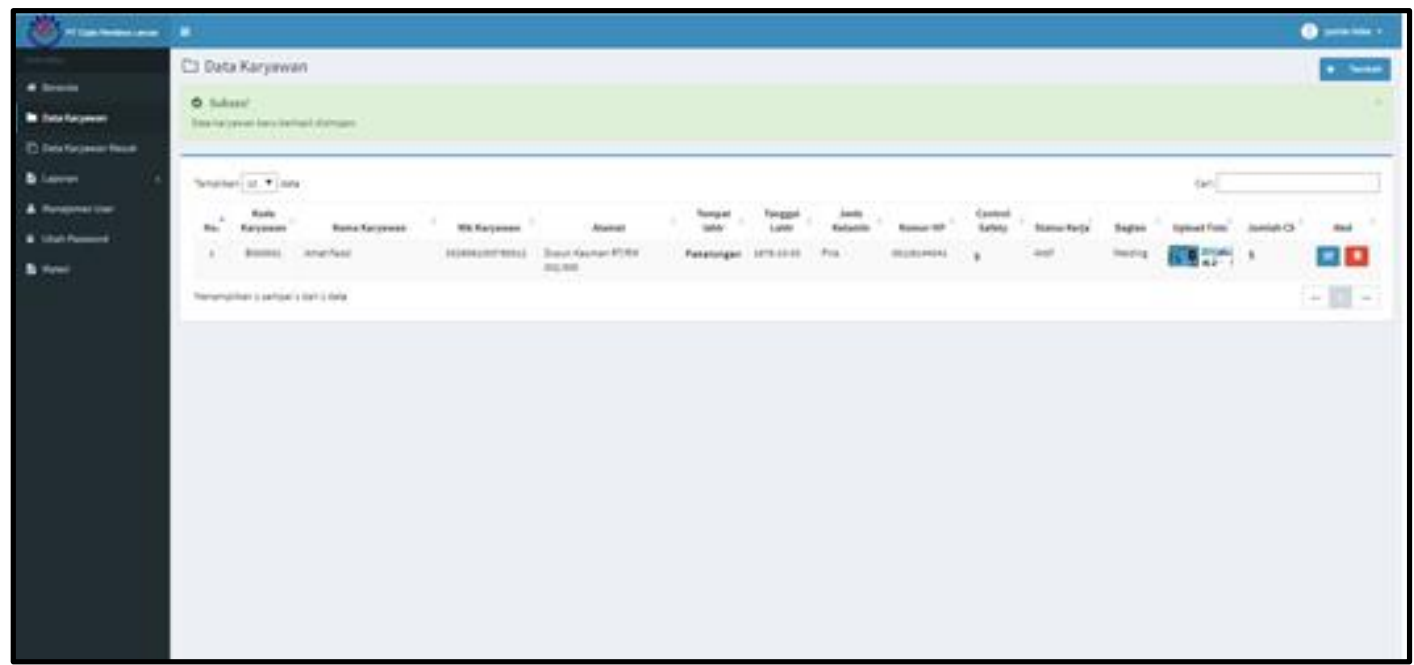

Gambar 8. Tampilan Menu Data Karyawan

Keterangan: Gambar 8 menjelaskan tentang Tampilan Menu Data Karyawan pada Web Sistem informasi pengelolaan data Occupational Health and Safety Handling yang dibuat untuk PT.CPL.

4. Tampilan Input Data Karyawan 


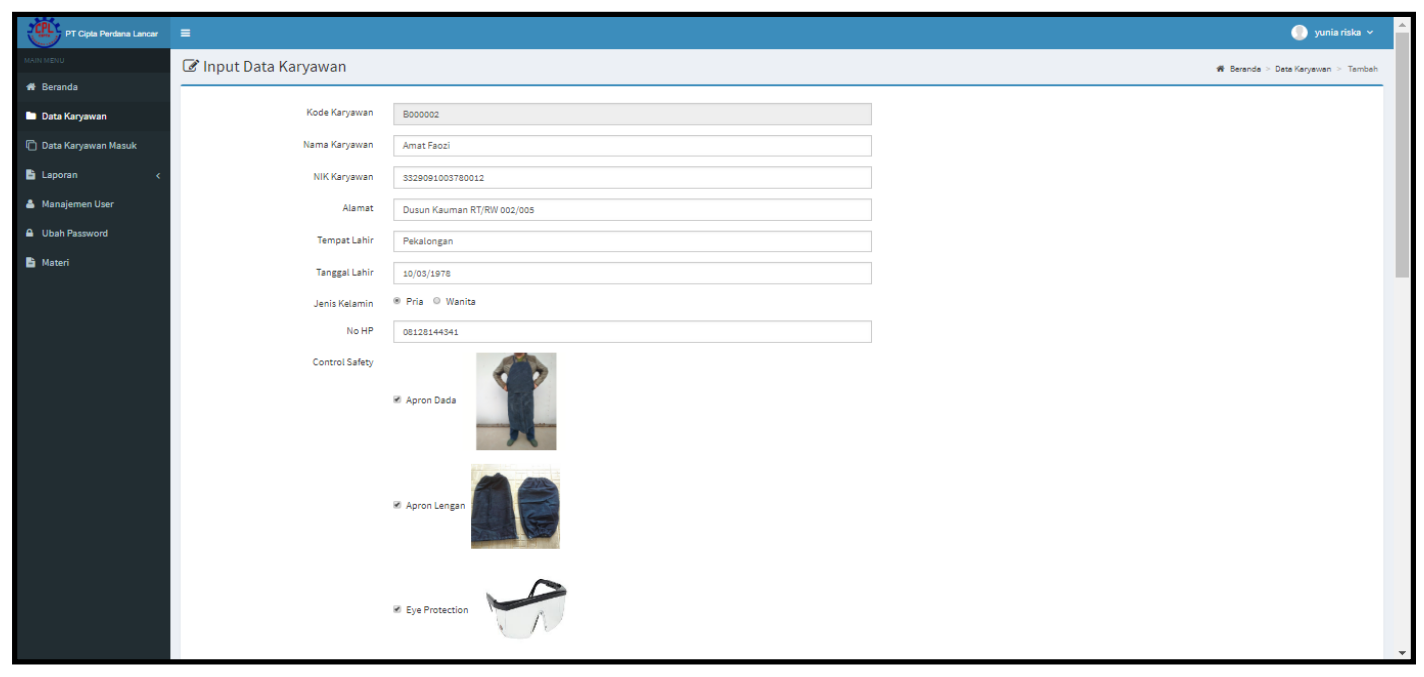

Gambar 9. Tampilan Input Data Karyawan

Keterangan: Gambar 9 menjelaskan tentang Tampilan Input Data Karyawan pada Web Sistem informasi pengelolaan data Occupational Health and Safety Handling yang dibuat untuk PT.CPL.

5. Tampilan Laporan Control Safety

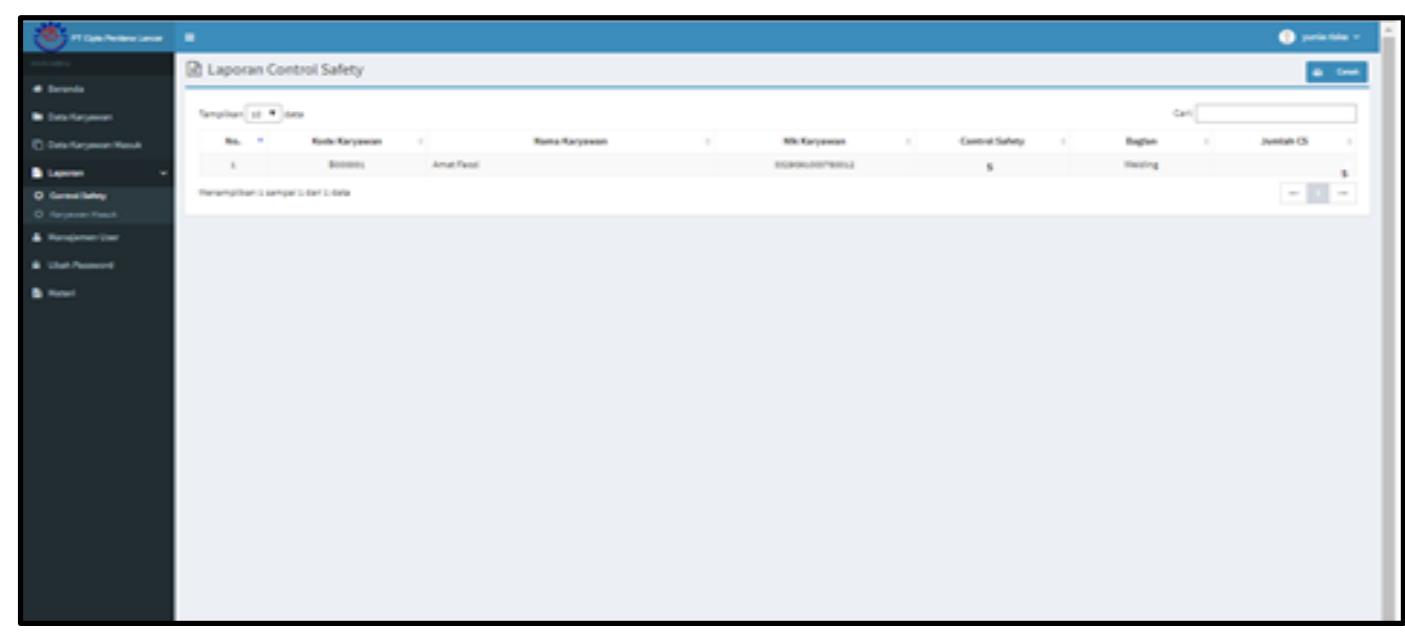

Gambar 10. Tampilan Laporan Control Safety

Keterangan: Gambar 10 menjelaskan tentang Tampilan Laporan Control Safety pada Web Sistem informasi pengelolaan data Occupational Health and Safety Handling yang dibuat untuk PT.CPL.

6. Tampilan Laporan Data Karyawan Masuk 


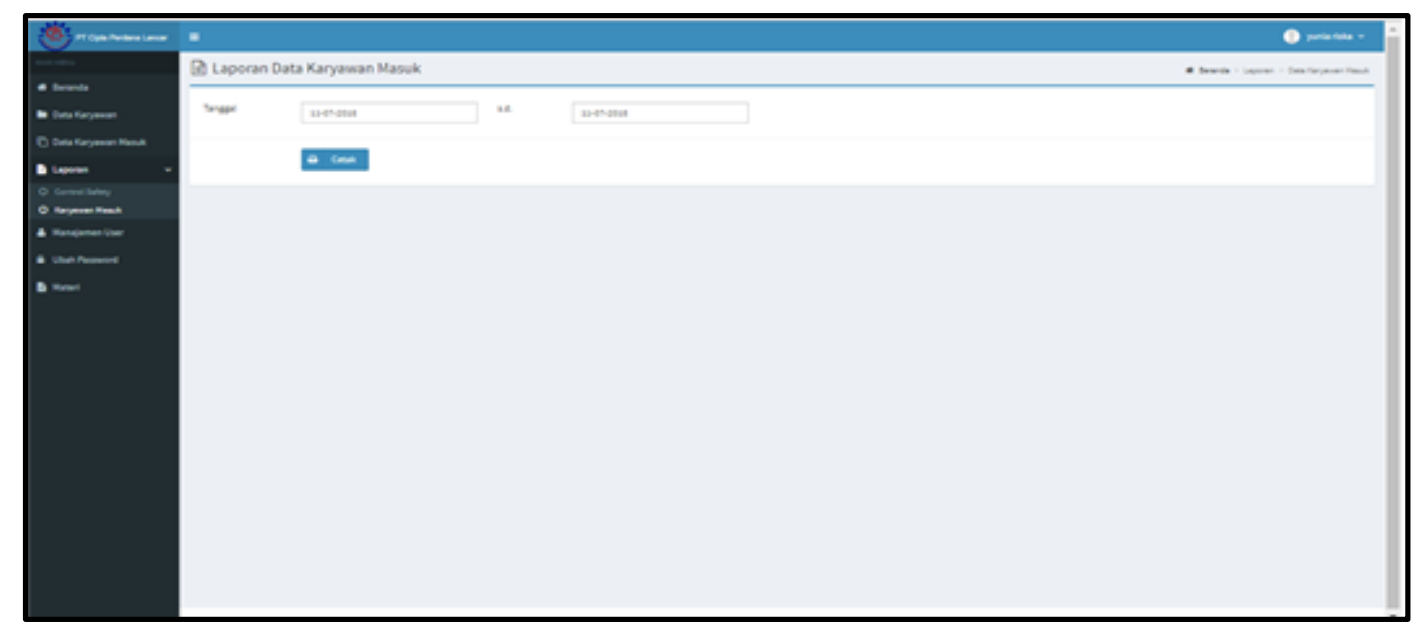

Gambar 11. Tampilan Laporan Data Karyawan Masuk

Keterangan: Gambar 11 menjelaskan tentang Tampilan Data Karyawan Masuk pada Web Sistem informasi pengelolaan data Occupational Health and Safety Handling yang dibuat untuk PT.CPL.

\section{KESIMPULAN}

Sistem informasi pengelolaan data Occupational Health and Safety Handling pada PT.CPL yang berjalan saat ini proses pengelolaan data karyawan dan kontrol safety-nya masih manual dan terdapat beberapa kekurangan, yakni jika terjadi kecelakaan kerja maka memerlukan waktu yang banyak untuk search data karyawan. Ini dikarenakan harus bertanya langsung kepada karyawan tersebut mengenai nomor ID BPJS dan ID KTP sehingga menyebabkan terjadinya keterlambatan laporan terhadap pihak BPJS. Kekurangan lainnya pada sisi sistem informasinya yang kurang tepat sehingga pada pelaksanaannya menjadi belum rapi dan belum terstruktur. Dengan kurang maksimalnya penanganan Occupational Health and Safety Handling tersebut karyawan menjadi tidak nyaman dalam bekerja. Untuk itulah perlu adanya suatu sistem informasi yang tepat sebagai solusi dari permasalahan tersebut, maka dari itulah penelitian ini dibuat yang kemudian menghasilkan sebuah Sistem informasi pengelolaan data Occupational Health and Safety Handling berbasis Web untuk PT.CPL.

\section{SARAN}

Disarankan agar Sistem informasi pengelolaan data Occupational Health and Safety Handling berbasis Web yang telah dibuat untuk PT.CPL dapat terus dikembangkan (delevoped) dan dilakukan Maintenance secara berkala agar tetap bisa digunakan dan bermanfaat untuk PT.CPL.

\section{DAFTAR PUSTAKA}

[1] Azizah, Nur. Nurlaila Suci Rahayu, Dewi Anjani. 2021. Rancang bangun sistem persediaan ATK berbasis Web pada Perumdam Tirta Kerta Raharja. Jurnal CERITA, Vol.7(1). 51.

[2] Triono, Zainul Hakim, dan Risky Amelia. 2018. Perancangan Aplikasi Dashboard Pengelolaan Hasil Produksi Departemen Finishing Berbasis Web Pada PT. Panarub Industry. Jurnal Sisfotek Global, 8(2), 84-89. 
[3] Nurul Nissa. Ulfa, dan Sholihati Amalia. 2017. Pengaruh Keselamatan dan Kesehatan Kerja Terhadap Kinerja Karyawan. Jurnal Riset Bisnis dan Investasi, 3(3), 69-77.

[4] Furotin Amalia. Vita. 2017. Pengaruh Keselamatan Dan Kesehatan Kerja (K3) Terhadap Produktivitas Kerja Karyawan (Studi Kasus Pada : PT. Paradise Island Furniture). Universitas Mercu Buana Yogyakarta.

[5] Dwi Putra. Ade., Elvi Syamsuir, dan Fatma Ira Wahyuni. 2021. Analisis Penerapan Kesehatan dan Keselamatan Kerja (K3) di Perusahaan Jasa Konstruksi Kota Payakumbuh. Rang Teknik Journal, 4(1), 76-82.

[6] Hasibuan. Rahman. 2017. Pengaruh Kesehatan dan Keselamatan Kerja, Pelatihan dan Kerja Tim Terhadap Kinerja Tenaga Medis Di Rumah Sakit Budi Kemuliaan Batam. Jurnal Dimensi, 6(2), 323-340.

[7] Moniaga. Fenny, dan Vanda Syela Rompis. 2019. Analisa Sistem Manajemen Kesehatan dan Keselamatan Kerja (SMK3) Proyek Kontruksi Menggunakan Metode Hazard Identification And Risk Assessment. Jurnal Ilmiah Realtech, 15(2), 65-73.

[8] Nurmianto. Eko, Nurma Anita, dan Apriani Nur Aulia. 2018. Identifikasi Hazard dan Perancangan Sistem Informasi Keselamatan dan Kesehatan Kerja Di Unit Amoniak (Studi Kasus: PT. Petrokimia Gersik). Jurnal Manajemen dan Teknik Industri Produksi, 82(1), 112-122.

[9] Syafrudin, Gusneli Yanti, dan Shanti Wahyuni Megasari. 2019. Penerapan Evaluasi Biaya Kesehatan dan Keselamatan Kerja (K3) Konstruksi Dalam Dokumen Perencanaan Teknis Pada APBN Di Lingkungan Dinas PUPR Provinsi Riau, Prosiding Seminar Nasional Cendekiawan. 